$\begin{array}{ll}\text { Kastamonu Eğitim Dergisi } & \\ \text { Kastamonu Education Journal } & \begin{array}{l}\text { Basvuru Tarihi/Received: } 05.01 .2018 \\ \text { Kays } 2019 \text { Cilt:27 Sayı:3 }\end{array}\end{array}$

\title{
Türkiye'deki STEM Merkezlerinin İncelenmesi ve STEM Merkezi Model Önerisi
}

\section{Examining The Stem Centres in Turkey and Stem Centre Model Proposal}

Öz

\author{
Mehmet Akif BiRCAN ${ }^{1}$, Çetin KÖKSAL ${ }^{2}$, Ahmet Turan CIMBIZ $^{3}$
}

Bu araştrrmada Türkiye'de STEM eğitimi veren merkezlerin durum analizlerinin incelenerek STEM merkezi modeli geliştirilmesi amaçlanmıştı. Tarama modellerinden genel tarama modeli kullanılan bu araştırmada veriler, "Yarı yapılandırılmış Görüşme Formu" ve "Yapılandırılmış Gözlem" notlarından elde edilmiş; betimsel analiz tekniği ile analiz edilmiştir. Çalışma grubu, Türkiye'deki üç ayrı STEM merkezi ve bu merkezlerde görev yapan öğretmenlerden oluşmaktadır. Araştırma sonucunda incelenen STEM merkezlerinin idari ve yapısal açıdan faklılık gösterdiği, kamu hizmetleri ve öğretim çerçevesinde yapılandıııldıkları tespit edilmiştir. Ayrıca STEM eğitim merkezlerinin çalışma usul ve esaslarını belirleyen bir çerçeve mevzuatta yoktur. Araştırma sürecinde incelenen STEM eğitim merkezlerinin ortak noktaları da kısıtlıdır. Araştırmadan elde edilen veriler doğrultusunda STEM merkezlerinin kurulması ve çalışmasını düzenleyen kriterlerin belirlenerek bir mevzuatın oluşturulması önerilmektedir.

Anahtar Kelimeler: stem, stem merkezi, stem merkezi modeli.

\section{Abstract}

In this research, it has been aimed to develop a STEM center model by examining the situation analysis of STEM centers in Tukey. The general scanning method is used from the scanning methods. In this study, the data were obtained from the "Semi-structured Interview Form" and "Structured Observation" notes and the data were analyzed by descriptive analysis technique. The working group is consisted of three separate STEM center in Turkey and the teachers working in these centers. As a result of the research, it was determined that the STEM centers examined differ from administrative and structural aspects and they are structured on the basis of public services and teaching. There is also no framework legislation that sets out the working procedures and principles of STEM education centers. The common points of the STEM education centers examined during the research process are also limited. It is proposed to establish a legislation by determining the criteria governing the establishment and operation of STEM centers in the direction of the data obtained from the research

Keywords: stem, stem center, stem center model.

1. Milli Eğitim Müdürlüğü, Tokat, Türkiye; https://orcid.org/0000-0003-2442-0600

2. Bilim ve Sanat Merkezi, Tokat, Türkiye; https://orcid.org/0000-0001-5415-1929

3. Akın İlkokulu, Tokat, Türkiye; https://orcid.org/0000-0002-4604-9294

Atıf / Citation: Bircan, M.A., Köksal, Ç., ve Cımbız, A.T. (2019). Türkiye'deki STEM merkezlerinin incelenmesi ve STEM merkezi model önerisi.Kastamonu Education Journal, 27(3), 1033-1045. doi:10.24106/kefdergi.2537 


\section{Extended Summary}

Introduction: In recent years, Japan, Korea, China, and many European Union countries, especially the United States of America (USA), have begun implementing STEM education at pre-school, primary and secondary levels with strong science and mathematical principals to create an innovative society. (Yılmaz, Koyunkaya vd., 2017). STEM education provides the development of competitive skills and STEM literacy in people based on an interdisciplinary approach. Countries have been reforming education systems to include global competitiveness and to raise qualified individuals in the direction of developments in the world. For educational reforms, it implements new training models and works to disseminate these new educational models to all the parts of the society. The most important of these models is STEM education. The most important task for the implementation and dissemination of STEM education has been given to the STEM education centers in the first step.

Method : The research which is intended to improve STEM Center Model that examined the situation analysis of the centers given STEM education in Turkey is a general scanning method of the scanning methods. The maximum diversity sampling method was used for the purposeful sampling methods to determine of the research sample. In this research, the data were obtained from the notes of "Semi-structured Interview Form" and "Structured Observation". The data were analyzed by descriptive analysis technique. The data of each center were collected under the headings formed by using the interview form and the observation notes, and then they were compared and interpreted.

Findings, Discussion and Results : The examined centers do not have a strategic plan in which their mission, vision and objectives are clearly defined. Strategic plans for STEM centers to be established are among the indispensable. With this plan, centers will be able to draw road maps for the future and update themselves constantly. It has been appeared that the centers surveyed operate around a main coordinator teacher and other co-ordinator teachers who assisted him or her. The lack of teachers at all school levels in STEM centers can be viewed as a weakness of centers. The organizational structures of these centers can be structured as a main coordinator and sub-coordinators (pre-school, primary school, secondary school and high school STEM coordinators).

In order to increase STEM education approach and awareness level, STEM in-service training courses should be organized in the Ministry of National Education, and STEM education approach should be moved to the classroom environment by being linked with curriculum programs.

There is no standard curriculum in STEM centers. While some centers are activity based activities, some centers continue their activities by preparing their own programs. A flexible framework for STEM centers should be established, targets should be defined but the strategies that will achieve these goals must be flexible.

Despite the financial and spiritual support of the municipalities, it seems that the supports on the basis of universities are minimal. For this reason, STEM centers should interact with local stakeholders by developing cooperation protocols.

In order to achieve the expected achievement of the STEM education approach, it is necessary that the STEM vocational qualifications of the teachers are increased, as well as the STEM life skills are supported and the students are made aware of the STEM career professions. It is seen that the centers are not troubled due to transportation. Given that the time periods during which students and teachers benefit from the STEM centers, it would be more appropriate to plan where STEM centers are located in urban centers with high school intensities. The STEM centers consist of different classes or workshops when compared with their physical characteristics. Although there are physical differences, similar activities are performed in all centers.

Although many commercial materials specific to the STEM educational approach have been developed, it would be wrong to consider these materials directly as STEM training material. It should not be forgotten that these materials will gain the STEM educational material characteristic according to the content of the training program prepared according to the STEM educational approach. It can be said that the construction of the STEM Centers in such a way as to provide service for seven days will be positive in terms of beneficiaries from the center. In cooperation with school teachers and STEM center teachers, students should be able to do activities in the STEM center during school hours. The use of STEM centers by students at every grade level remains very has been limited. STEM centers should be structured to cover every student from pre-school through to secondary and even higher education.

The social, cultural and sports activities of the STEM centers seem to be rather limited. When it is thought that these centers are newly established centers, it can be said that many of the projects to be carried out in these centers in the process will be very effective in eliminating deficiencies in this area. 


\section{Giriş}

Yirminci yüzyılda hız kazanan küresel ekonomik yarış ile birlikte bilim ve teknolojide hızlı gelişme ve değişmeler meydana gelmektedir. Bu gelişim ve değişim, bu gelişmelerin içerdiği fen, matematik ve mühendislik boyutlarının farkında olan bireylere olan intiyacı artırmıştı. Başta Çin, Japonya, Amerika Birleşik Devletleri gibi ülkeler olmak üzere Avrupa ve Asya'daki birçok ülke, bilim ve teknolojide ilerleme kaydetmek için fen, teknoloji, mühendislik ve matematik alanlarındaki disiplinler arası entegrasyona önem verilmesi gerektiğini vurgulamaya başlamıştı (Akgündüz ve Ertepınar, 2015). Bu düşünceden hareketle, son yıllarda Amerika Birleşik Devletleri (ABD) başta olmak üzere Japonya, Kore, Çin ve birçok Avrupa Birliği ülkesi yenilikçi bir toplum oluşturmak için sağlam fen ve matematik temelini içeren STEM (Science, Technology, Engineering, Mathematics) eğitimini okul öncesi, ilköğretim ve ortaöğretim seviyelerinde uygulamaya başlamıştır (Yılmaz, Koyunkaya vd., 2017).

STEM eğitimi, disiplinlerarası bir yaklaşımla STEM konularıyla ilgili bilgi, beceri ve inançları geliştiren bir yaklaşım olarak benimsenmektedir (Corlu, Capraro ve Capraro, 2014). STEM eğitimi, disiplinler arası bir yaklaşımı temel alarak kişilerin rekabet yeteneğinin ve STEM okuryazarlığının gelişimini sağlar. STEM eğitimi, küresel girişimciliğe katkı yapar ve okul, toplum, iş arasında bağlantıları kurmayı sağlar. Bütün bunlarla birlikte, öğrencilerin fen, teknoloji, mühendislik ve matematik alanları arasında bağlant kurmalarını ve bu bağlantıları uygulamalarını sağlar (Thomas, 2014).

STEM eğitimi modeli, gelişmiş ve gelişmekte olan birçok ülkenin öğretim programlarında, standartlarında, okul içi ve okul dışı aktivitelerde uygulanmaya başlanmıştır. Ülkemizde de son yıllarda, Milli Eğitim Bakanlığı tarafindan hazırlanmış olan öğretim programlarında açıkça yer almasa da, STEM eğitimi alanında yapılan çalışmalar ve uygulamalar hızla artmaktadır (Çorlu, 2014; Çorlu, Capraro ve Capraro, 2014). Bu anlamda Milli Eğitim Bakanlığı (2016) tarafindan STEM Eğitim Raporu'nu yayınlanmış ve ülkemizde STEM eğitiminin yaygınlaştırılması için bir eylem planı hazırlanmıştır. Bakanlık tarafindan yürütülmesi önerilen STEM Eğitimi Eylem Planı'nın aşağıdaki adımlardan oluşmasının yerinde olacağı ifade edilmektedir: -STEM Eğitimi merkezlerinin kurulması, -Bu merkezlerde üniversitelerle işbirliği içerisinde STEM eğitimi araştırmalarının yapılması, -Öğretmenlerin STEM eğitim yaklaşımını benimseyecek şekilde yetiştirilmesi, -Öğretim programlarının STEM eğitimini içerecek biçimde güncellenmesi, -Okullardaki STEM eğitimi için öğretim ortamlarının oluşturulması ve ders materyallerinin sağlanması.

Milli Eğitim Bakanlığı tarafindan yürütülmesi planlanan STEM Eğitimi Eylem Planı́nın ilk adımı doğrultusunda milli eğitim müdürlüklerince, belediyelerce; STEM eğitim raporu yayınlanmadan önce özel üniversite ve teşebbüslerce STEM merkezleri kurulmuştur. STEM eğitimi merkezleri, Amerika Birleşik Devletleri başta olmak üzere birçok ülkede üniversitelerde, bağımsız özel kuruluşlarda ve informel ortamlarda STEM eğitimine odaklanmış kurumlardır (Karahan, 2017).

STEM eğitim merkezlerinin; (a) STEM odaklı lisans programlarını geliştirme, (b) STEM odaklı hizmet öncesi ve hizmet içi öğretmen eğitimleri geliştirerek uygulama ve (c) toplumla etkileşime geçerek bulundukları kurum ve yörede yaygın bir etki oluşturma amaçları vardır. STEM eğitim merkezleri, genel manada STEM eğitim reformunun daha iyi anlaşılarak hayata geçirilmesi amacıyla kurulmuş olsalar da bu merkezlerin yapıları incelendiklerinde (1) hedef kitleleri, (2) vizyon ve misyonları, (3) kaynak ve finansman düzeyleri, (4) fiziksel alan ve istihdam açısından boyutları, (5) deneyimleri, (6) konumlandırılmaları açısından farklılıklar göstermektedirler. STEM eğitim merkezlerinin çalışma yapıları incelendiğinde, bu merkezlerin "araştırma", "öğretim ve "kamu hizmetleri" şeklinde üç temel alan üzerinde yapılandığı görülmektedir. Ulusal ve uluslararası düzeyde STEM eğitim merkezlerinin üç farklı şekilde yapılandırıldığı görülmektedir. Bunlardan en yaygın olanı, üniversiteler bünyesinde yer alanlardır. Bunların yanı sıra bağımsız kişi ve kurumların inisiyatifi ile kurulan merkezler de bulunmaktadır. (Karahan, 2017). Son olarak, yapılandırılmasının odak noktasında STEM eğitimi olan ve bu mantıkla çalışan merkezler de bulunmaktadır. Bunlar, bilim merkezleri, akvaryum ve müzeler gibi informal öğrenme ortamlarıdır.

Ülkeler, son yıllarda yaşanan gelişmeler doğrultusunda; küresel rekabete dâhil olabilmek ve nitelikli bireyler yetiştirebilmek için eğitim sistemlerinde reformlar yapmaktadır. Eğitim reformları için, yeni eğitim modellerini uygulamakta ve bu yeni eğitim modellerini toplumun bütün kesimlerine yaymak için çalışmalar yürütmektedir. Bu modellerden en önemlisi de yukarıda sözü edilen STEM eğitimidir. STEM eğitiminin uygulanması ve yaygınlaştırılması adına en önemli görev, ilk aşamada STEM eğitim merkezlerine düşmektedir. Bu bilgi ışı̆ıında, ülkemizde STEM eğitim merkezlerinin kurulması, bu merkezlerin uluslararası düzeyde kurulan merkezlerin kuruluş ve işleyiş modelleri ile uyumlu olması önemli görülmektedir. 


\section{Araştırmanın Amacı}

Bu araştırmada, Türkiye'de STEM eğitim yaklaşımı alanında faaliyet gösteren merkezlerin durum analizlerinin incelenerek ortaya konulması ve bu bilgiler ışığında Türkiye için örnek bir STEM merkezi modeli geliştirilmesi amaçlanmıştır.

\section{Araştırmanın Önemi}

Dünyada ve Türkiye'de popüler durumda olan STEM eğitim yaklaşımının beklenilen başarıyı yakalayabilmesi için, öncelikle STEM kültürünün tüm paydaşlarca içselleştirilmesi gerekmektedir. Bu aşamada, devreye STEM merkezleri girmektedir. STEM eğitim yaklaşımına uygun bir şekilde kurgulanan merkezler, STEM kültürünün tüm paydaşlarda yapılandırımasına yardım edecektir. Böylelikle STEM alanında nitelikli okulların gelişimine, dolayısıyla da küresel rekabete girebilecek nitelikli bireylerin yetişmesine de katkı sağlanmış olacaktır. Araştırma sonucunda geliştirilecek olan STEM merkezi modeli, kurulması düşünülen diğer STEM merkezlerine yol gösterici nitelikte olacaktır.

\section{Yöntem}

\section{Araştırmanın Modeli}

Türkiye'de STEM eğitimi veren merkezlerin durum analizlerinin incelenerek STEM merkezi modeli geliştirilmesi amaçlanan bu araştırma, tarama modellerinden genel tarama modelinde bir çalışmadır. Tarama modelinde konu, olay, birey, nesne kendi mevcut durumları içinde değiştirilme veya etkileme amacı güdülmeksizin gözlenip belirlenir (Karasar, 2008; 77). Tarama modelleri içinde belirtilen genel tarama modelinde, evren hakkında genel bir yargıya varmak için evreni oluşturan elemanların tamamında veya bir örneklemi üzerinde tarama yapılmaktadır (Karasar, 2008;79).

\section{Araştırmanın Evren ve Örneklemi}

Araştırma evrenini Türkiye'deki STEM merkezleri oluşturmaktadır. Araştırma örnekleminin belirlenmesinde, amaçlı örnekleme yöntemlerinden kolay ulaşılabilir durum örneklemesi yöntemi kullanılmıştır. Buradaki amaç, araştırmaya hız ve pratiklik kazandırmaktır. Çünkü bu yöntemle araştırmacı, yakın ve erişilmesi kolay olan bir durumu seçer (Yıldırım ve Şimşek, 2008). Buradan hareketle araştırma örneklemine; ülkemizin üç farklı coğrafi bölgesinde faaliyet gösteren STEM merkezleri seçilmiştir. Örneklemdeki STEM merkezlerinden ikisi il milli eğitim müdürlüklerine bağlı olarak faaliyet gösterirken, birisi de ilçe belediyesine bağlı olarak faaliyet göstermektedir. Bunlar resmi nitelikte kurumlardır. Araştırmada STEM merkezleri, numara verilerek kodlanmıştır. Araştırmanın örneklemini oluşturan STEM merkezlerinin bulundukları coğrafi bölgeleri ve ziyaret tarihleri Tablo 1'de gösterilmiştir.

\section{Tablo 1. Ziyaret Edilen STEM Merkezleri ve Ziyaret Tarihleri}

\begin{tabular}{lll}
\hline Ziyaret Edilen STEM Merkezleri & Bulunduğu Coğrafi Bölge & Ziyaret Tarihi \\
\hline 1.Merkez & Güneydoğu Anadolu Bölgesi & 26 Temmuz 2017 \\
2. Merkez & Akdeniz Bölgesi & 27 Temmuz 2017 \\
3.Merkez & İç Anadolu Bölgesi & 28 Temmuz 2017 \\
\hline
\end{tabular}

Araştırmada ziyaret edilen STEM merkezlerinin koordinatörlük görevini yürütenler ile görüşmelere yapılmıştır. Bu kişilere ait bilgiler Tablo 2'de gösterilmiştir.

Tablo 2. Görüşme Yapılan STEM Merkezi Koordinatörlerine Ait Bilgiler

\begin{tabular}{lllll}
\hline Kod & Görev Yaptı̆̆ı STEM Merkezi & Branşı & Kıdem yılı & Cinsiyet \\
\hline K1 & 1.Merkez & Rehber Öğretmen & 7 & Erkek \\
K2 & 2.Merkez & Fen Bilimleri & 9 & Erkek \\
K3 & 3.Merkez & Fen Bilimleri & 15 & Erkek \\
\hline
\end{tabular}

Araştırmada gizlilik ilkesine uygun olarak her katılımcıya bir kod numarası verilmiştir. Katılımcılar K1, K2 ve K3 olarak kodlanmıştır.

\section{Araştırmanın Veri Toplama Araçları}

Araştırmadaki veriler, "Yarı Yapılandırılmış Görüşme Formu" verilerinden ve "Yapılandırılmış Gözlem Formu" notlarından elde edilmiştir. Bu formların hazırlanması sürecinde araştırmacılar tarafindan STEM merkezlerine yönelik alan taraması yapılmış, incelenecek merkezlere yönelik ölçütler belirlenmiştir. Bu ölçütler doğrultusunda görüşme ve gözlem formları oluşturulmuştur. Hazırlanan formlara yönelik 3 uzman görüşü alındıktan sonra formlara son şekli verilmiştir. 
Önceden bilgilendirilen katılımcılarla yapılan tüm görüşmeler, ses kayıt cihazı kullanılarak kayıt altına alınmıştr. Gözlem notlarıyla ve görüşme formuyla elde edilen verilerin desteklenmesi amacıyla fotoğraflardan yararlanılmıştr. Görüşme formları ve gözlem notları iki araştırmacı tarafindan ayrı ayrı tutularak raporlaştırma aşamasında veriler birleştirilmiştir. Oluşturulan görüşme formundaki sorulardan bazıları aşağıdaki gibidir:

1. Kurumunuzun misyon, vizyon ve hedefleri nelerdir?

2. Kurumunuzun organizasyon yapısı nasıldır? Açıklayınız.

3. Kurumunuzda uygulanan öğretim programları ve oluşturulma süreci hakkında bilgi verir misiniz?

Görüşme yapılan kişiler arasındaki benzerlik ve farklılıkları saptamak amacıyla yapılandırılmış görüşme yöntemi kullanılır (Brannigan, 1985; Aktaran: Yıldırım ve Şimşek, 2000; 93). Yapılandııımış görüşmede ne tür verilerin elde edilebileceği ayrıntlı bir şekilde planlanır ve görüşme planı aynen uygulanır (Karasar, 2008; 167). Yarı yapılandırılmış görüşme formuyla: merkezin vizyon, misyon ve hedefleri, merkezin organizasyon yapısı, merkezde izlenilen eğitim programları, merkezin yerel ve ulusal paydaşlarla işbirlikleri, merkezin rehberlik faaliyetleri, merkezin fiziki yapısı, merkezde kullanılan eğitim materyalleri, merkezdeki etkinlik zamanları, merkezden faydalanan öğrencilerin okul türleri ve sınıf seviyeleri, merkezdeki öğretmenlerin çalışma süreleri hakkında bilgiler elde edilmeye çalışılmıştır. Yapılandırılmış gözlem çalışmaları, araştırmacının gözlem yapılacak ortamda yer aldığı ve gözlenecek olan davranışın doğal ortamında yapıldığı gözlem çalışmalarıdır (Yıldııım ve Şimşek, 2008; 125). Yapılandırılmış gözlem yöntemiyle merkezdeki farklı etkinlik örnekleri, merkezlerin güçlü ve zayıf yönleri tespit edilmeye çalışılmıştı. Fotoğraf makinesi ile gözlemler kayıt altına alınmış; bir yandan da araştırmacılar tarafindan yapılandırılmış gözlem formu doldurulmuştur. Oluşturulan gözlem formundaki maddeler aşağıdaki gibidir:

1. STEM merkezinin şehirdeki konumu.

2. STEM merkezinin fiziki özellikleri.

3. STEM merkezinde kullanılan materyaller ve yazılımlar.

\section{Araştırma Verilerinin Analizi}

Araştırmada elde edilen veriler, betimsel analiz tekniği ile analiz edilmiştir. Betimsel analizde veri toplama araçlarıyla elde edilen bulguların düzenlenip yorumlanarak okuyucuya sunulması amaçlanmaktadır (Yıldııım ve Şahin, 2008; 159).

Yarı yapılandırılmış görüşme formundaki veriler ses kayıtları ile karşılaştıılarak verilerin anlam kaybı olmadan betimlenmesi gerçekleştirilmiştir. Her bir merkezin verileri, görüşme formundaki başlıklar ve gözlem notlarından yararlanılarak oluşturulan başlıklar altında toplanıp karşılaştırması ve yorumlanması yapılmıştr.

\section{Bulgular}

Araştırmadan elde edilen bulgular iki başlık altında toplanmıştır.

\section{STEM Merkezlerine Yönelik Yarı Yapılandırılmış Görüşme Formuyla Elde Edilen Bulgular}

STEM Merkezlerin misyonu, vizyonu ve hedefleri üzerine yapılan inceleme sonuçları Tablo 3'te gösterilmiştir.

\section{Tablo 3. STEM Merkezlerinin Misyon, Vizyon ve Hedefleri}

\begin{tabular}{|c|c|c|c|}
\hline & Misyon & Vizyon & Hedef \\
\hline \multirow{4}{*}{ 1.Merkez } & \multirow{4}{*}{$\begin{array}{l}\text { Bilimsel faaliyetlere yatkın } \\
\text { tüm öğrencilere STEM mo- } \\
\text { dülleri ışığında eğitimler ve- } \\
\text { rilerek geleceğin mühendis } \\
\text { adaylarına ortam hazırla- } \\
\text { mak. }\end{array}$} & - & STEM çalışmalarını il geneline yaymak, \\
\hline & & & $\begin{array}{l}\text { İl genelinde öğrenim gören öğrencilerin okulda öğrendiklerini ürüne dönüş- } \\
\text { türebilmelerini sağlamak, }\end{array}$ \\
\hline & & & $\begin{array}{l}\text { İl genelinde öğrenim gören öğrencilerin öğrendikleri ile gerçek yaşam beceri- } \\
\text { leri arasında bağ kurulabilmelerini sağlamak, }\end{array}$ \\
\hline & & & $\begin{array}{l}\text { Öğrencilerin mühendislik mesleklerini tanımaları ve bu alanlara ilgi duyma- } \\
\text { larını sağlamak. }\end{array}$ \\
\hline 2.Merkez & - & - & - \\
\hline 3.Merkez & - & - & - \\
\hline
\end{tabular}

Tabloda verilen bilgiler katılımcıların aşă̆ıdaki ifadelerini destekler niteliktedir:

"K1: Bir ortaokulda başladığımız STEM çalışmalarını nasıl il geneline yayabiliriz diyerek bir merkez kurduk. Bu amaçla da hedeflerimizi bu doğrultuda belirledik. İlimizdeki öğrencilerin okulda elde ettikleri bilgileri 
günlük hayatta kullanabilmelerini, ürüne dönüştürmelerini sağlamak, bir meslek seçimi yaptkkları zaman bir mühendis oldukları zaman meslek hayatında nelerle karşılaşacaklarını, neler yapacaklarını temel seviyede kavratmak hedeflerimizdir. Merkezimizin misyonu da bahsettiğimiz hedefleri kapsayacak ve bize yol çizecek şekilde bilimsel faaliyetlere yatkın tüm öğrencilere STEM modülleri ışığında eğitimler verilerek geleceğin mühendis adaylarına ortam hazırlamak olarak ifade edebilirim."

Inceleme yapılan STEM merkezleri; misyon, vizyon ve hedeflerinin net olarak belirlendiği herhangi bir stratejik plana sahip değildirler. Tablo 3'te görüldüğü üzere misyon, vizyon ve hedeflerini belirleyen tek merkez, birinci merkezdir. Diğerleri, bu konuda herhangi bir çalışma yapmamıştı. Birinci merkez için verilen bilgilerin de STEM merkezi koordinatörünün sözlü beyanlarıyla sınılı kaldığı gözlemlenmiştir. STEM merkezlerinin organizasyon yapısına yönelik bilgiler Tablo 4'te verilmiştir.

\section{Tablo 4. STEM Merkezlerinin Organizasyon Yapıları}

Merkezde Milli Eğitim Müdürlüğü AR-GE biriminde görevlendirilmiş dört öğretmen görev yapmaktadır. Bu öğretmenlerden bir tanesi kurumun koordinatörlüğünü yürütmekte diğer öğretmenler ise ilgili branşlarda öğretmen eğitimleri ve öğrencilere yönelik atölye çalışmaları yürütmektedir. Kurumda görevli olan öğretmenlerin branşları;

1.Merkez Rehber Öğretmen (Koordinatör), Matematik, Bilişim ve Fen Bilimleridir. Ayrıca kurumda görevli öğretmenlere yardımcı olan meslek lisesi 12. Sınıf öğrencileri de görev yapmaktadır. Merkez maddi ihtiyaçlarının bir çoğunu projeler vasıtasıyla karşılamaktadır. Merkezde görev alan koordinatör öğretmen AB projesi ile STEM eğitimcisi eğitimlerine katıımıştr. Diğer üç öğretmen il genelinde verilen STEM Temel Seviye ve STEM ileri Seviye eğitimleri sırasında bu alana ilgisi ve yeteneği doğrultusunda seçilmiştir. Kurumun işleyişi projeler destekli olarak devam etmektedir.

2.Merkez Merkez, ilçe belediyesi bünyesinde kurulmuştur. Milli Eğitim bünyesinde çalışan iki öğretmen (Fen Bilimleri, Özel Eğitim) merkezin koordinatörlüğünü yürütmektedir. Diğer beş öğretmen belediye tarafindan istihdam edilmiştir.

Merkez, il Milli Eğitim Müdürlüğü bünyesinde AR-GE birimine bağlı bir öğretmen akademisi olarak kurgulanmıştr.

3.Merkez Merkezde tam zamanlı AR-GE biriminde bir öğretmen (koordinatör) ayrıca okullarında görev yapan yarı zamanlı üç öğretmen görev yapmaktadır.

Tabloda verilen bilgiler katılımcıların aşağıdaki ifadelerini destekler niteliktedir;

“K2: Merkezimiz ilçe belediyemizin bünyesinde kuruldu. Bir hafta süre ile eğitim verdiğimiz öğretmenlerimiz merkezimizde görev yapıyor. Bizler iki öğretmen olarak merkezin koordinatörlüğünü yapıyoruz. Bizler ilçede yer alan devlet okullarında öğretmeniz. Fakat bizim dışımızda merkezde görev yapan öğretmenler belediye tarafindan istihdam edilmektedir. Ücret ve diğer sosyal hakları belediye tarafindan karşılanmaktadır."

"K3: İl milli eğitim bünyesinde görev yapan bir merkeziz. Ayrı bir binada görev yapıyoruz. Ayrıca merkeze dışarıdan üç öğretmen destek vermektedir. Dışarıdan derken okullarında göreve devam eden öğretmenlerimiz. Merkezimiz organizasyon yapısı olarak milli eğitime bağı diyebiliriz."

STEM merkezlerinin idari yapıları incelendiğinde, ikisinin Milli Eğitim Müdürlükleri, birinin ise bir belediye tarafindan kurulduğu görülmektedir.

STEM merkezlerinin iyileştirmeyi düşündükleri yanları Tablo 5'te verilmiştir.

\section{Tablo 5. STEM Merkezlerinin İyileştirmeyi Düşündükleri Yanları}

STEM eğitimini il genelindeki tüm okullara yayabilmek,

1.Merkez Okullarda STEM merkezlerinde çalışacak öğretmenlerin, STEM eğitimi modeline yönelik mesleki yeterliliklerini artrabilmek.

Öğrencilerin merkezden daha fazla yararlanabilmelerini sağlayabilmek,

2.Merkez Hizmet binasının daha merkezi bir konuma taşınmasını sağlayabilmek,

STEM'in bir eğitim modeli-yaklaşımı olduğunu hizmet verdiği eğitim bölgesine daha fazla yayabilmek.

Kurumda STEM materyali eksikliğini giderebilmek,

3.Merkez

STEM eğitimini dar kapsamdan çıkarıp tüm öğretmenlere yayabilmek.

Tabloda verilen bilgiler kathlımcıların aşağıdaki ifadelerini destekler niteliktedir;

"K3: En büyük eksikliğimiz malzeme eksikliği. Aynı zamanda kısır döngüyü yıkabilmek. STEM sadece malzeme değil pahalı malzeme değil. Atk malzemeden ucuz malzemeden de yapabilmek. Bunu yaygınlaştırarak STEM'i yaymak. İyileştirmeyi düşündüğümüz yanlarımız. " 
STEM merkezlerinin iyileştirmeyi düşündükleri yanları; STEM eğitimini il genelindeki okullara yayabilmek, öğretmenlerin STEM eğitimi modeli mesleki yeterliliklerini artrabilmek ve daha fazla öğrencinin merkezlerden faydalanabilmesini sağlamaktır. Ayrıca merkezlerin iyileştirmeyi düşündükleri arasında kurumların fiziki ve öğretim materyali eksikliklerini gidermek de yer almaktadır. . STEM merkezlerinde izlenilen eğitim programları ve bu programların geliştirilme süreçleri hakkında bilgiler Tablo 6'da verilmiştir.

\section{Tablo 6. STEM Merkezlerinde İzlenilen Eğitim Programı ve Eğitim Programlarının Geliştirilmesi Süreci}

1.Merkez öğrenciler için standart bir eğitim programı uygulanmaktadır. Bu eğitim programının içeriğini de kurumun ve STEM eğitiminde kullanılacak materyallerin tanıtımı oluşturmaktadır. Kurumda öğrencilere yönelik çalışmalar randevu sistemiyle belirlenen gün ve saatte, bir ya da birkaç atölye çalışması ile sınırlı kalmaktadır.

Merkezde uygulanan bir eğitim programı mevcuttur. Bu program okul müfredat ile paraleldir. Okul müfredat programı

2.Merkez doğrultusunda her öğretmen günlük plan hazırlamakta ve bu planlar koordinatör öğretmenler tarafindan incelenerek merkezde uygulanabilmektedir. Kurum 16.30-20.00 saatleri arasında hizmet vermektedir. Merkezde 3.sınıftan başlayarak 10. Sınıfa kadar olan tüm öğrencilere eğitim verilmektedir. Kurumda öğretmen eğitimleri de yapılmamaktadır.

Merkezde uygulanan bir eğitim programı mevcuttur. Eğitim-öğretim yılı içerisinde kazanımlara paralel olarak öğret3.Merkez menlere verilecek eğitimler planmış ve öğretim programı oluşturulmuştur. 26 okula STEM eğitiminde kullanılabilecek malzemeler gönderilmiş ve 80 öğretmene STEM temel seviye eğitimi verilmiştir.

Tabloda verilen bilgiler katılımcıların aşağıdaki ifadelerini destekler niteliktedir;

“K3:Sabit taslak programı kendimiz oluşturduk. Kendi kazanımlarımızı oluşturduk. Yani normal bir yere gideceğimiz zaman bir programımız var. Öğretmenlere temel eğitim, ileri eğitim ve eğitici eğitimi olmak üzere birer haftalık programlarımız var. Yıllık çalışma planımız belli. Hangi ay ne yapacağımız belli. Ama tabi bunu zaman zaman yer değişikliği ile kısıtlı olmak şartiyla yapıyoruz."

STEM merkezlerinde izlenilen standart bir eğitim-öğretim programı yoktur. Bazı merkezler, etkinlik temelli bazı merkezler de kendi hazırladıkları program doğrultusunda faaliyetlere devam etmektedir. STEM merkezleri ile mezun etmiş oldukları öğrenciler arasındaki etkileşim süreci hakkındaki bilgiler Tablo 7'de verilmiştir.

\section{Tablo 7. STEM Merkezlerinin Mezunlarla Olan Etkileşim Süreçleri}

Merkezde şimdiye kadar 126 öğretmene STEM Temel Seviye ve STEM ileri Seviye Eğitimleri verilmiştir. Öğretmenlere

1.Merkez yönelik eğitimler devam etmektedir. Merkezdeki öğrencilere yönelik etkinlikler eğitim verilen öğretmenlerin okullarında planladıkları STEM etkinlikleri ile merkezde görev yapan öğretmenlerin etkinlikleri ile koordineli bir şekilde uygulanmaktadır. Merkezden mezun olan öğrenci mevcut değildir.

2.Merkez Merkez devam eden öğrencileri ilgi ve tutum ölçekleri ile izlemektedir. Bu öğrencilerin okul akademik başarıları da takip edilmektedir.

3.Merkez Eğitim verilen öğretmenler, belirli periyotlarla okullarında ziyaret edilmektedir. Ayrıca öğretmenlerle yılsonunda bilim festivali yapılarak öğrenci ve öğretmen ürünleri sergilenmektedir.

Tabloda verilen bilgiler katılımcıların aşağıdaki ifadelerini destekler niteliktedir;

“K2: Bizim öğrencilerimiz ile okullarda iletişimimiz ve takibimiz sürekli. Bizde eğitime başlayan her öğrenci için bir dosya oluşturulur. Bu süreçte okul idareleri aracılığı ile akademik başarıları takipteyiz. Hem de burada (merkezde) uyguladığımız tutum ve ilgi ölçekleri ile öğrencilerimizi izliyoruz."

"K3: Bir okullara ziyarete gidiyoruz. İki eğitime katılan öğretmenlerimizle bir bilim festivali düzenledik. Eğitim verdikten sonra bir yarışma sürecimizde oluyor. Öğretmenlerimiz bu sürecin sonunda yaptıkları ürünleri gelip sergilediler. Bu şekilde iletişimimiz devam ediyor."

STEM eğitimi, ülkemizde yeni uygulanmaya çalışılan bir yaklaşımıdır. Kurulan STEM merkezlerinin de birkaç yıllık merkezler oldukları düşünüldüğünde, mezun olan öğrenci bulunmaması gayet normal olarak karşılanabilir. Ancak bu merkezler de eğitim alan (mezun) öğretmenlerin, milli eğitim çatısı altında kurulan merkezlere desteklerini sürdürdükleri görülmektedir (Tablo 7). Bu durum, STEM eğitim yaklaşımının doğasına da uygundur. Ekip olarak çalışmak, öğrencileri eğitmek, eğitilenlerle STEM eğitimlerine devam etmek, STEM eğitim yaklaşımından beklenen başarıya ulaşmamızda önemli bir etken olacağını söylemek mümkündür. Tablo 7 incelendiğinde sadece bir merkez, öğrencileri hem etkinlikler sonunda hem de okul eğitimi sırasında takip etmektedir. STEM eğitiminde de olması gereken budur. Öğrenciler bu merkezlerden sürekli olarak faydalanmalı ve süreç içerisinde öğrencilerin takibi kesinlikle yapılmalıdır. Öğrenciler bu merkezlerden mezun olsalar dahi iletişim kopukluğuna meydan vermeden sıkı bir şekilde takibi yapılmalıdır. 
Gerektiğinde mezun öğrencilerin STEM merkezlerinde görev almaları sağlanabilir. STEM merkezlerinin diğer kurumlarla protokolleri ve işbirliklerine yönelik bilgiler Tablo 8'de verilmiştir.

\section{Tablo 8. STEM Merkezlerinin Diğer Kurumlarla Protokolleri ve Işbirlikleri}

\begin{tabular}{ll}
\hline 1.Merkez & $\begin{array}{l}\text { Merkezin diğer kurumlarla belirlenmiş bir protokolü bulunmamaktadır. Fakat merkez Büyükşehir Belediyesi ile } \\
\text { işbirliğini sürdürmektedir. Büyükşehir Belediyesi STEM merkezine ve STEM merkezi öğrencilerine sürekli olarak } \\
\text { maddi destek sağlamaktadır. }\end{array}$ \\
\hline 2.Merkez & Merkezin herhangi bir kurumla protokolü ve işbirliği bulunmamaktadır. \\
\hline 3.Merkez & $\begin{array}{l}\text { Merkezin il içerisindeki üniversitelerle, bulunduğu belediye ve büyükşehir belediyesi ile işbirliği protokolleri mev- } \\
\text { cuttur. }\end{array}$ \\
\hline
\end{tabular}

Tabloda verilen bilgiler katılımcıların aşağıdaki ifadelerini destekler niteliktedir;

“K1: Belirli bir protokolümüz yok. Ama büyükşehir belediyemiz ile işbirliğimiz mevcut. Bizlere büyük katkıları oluyor. Burası büyük bir şehir. Çağ nüfusu da bir hayli fazla. Bu noktada merkeze öğrencilerin gelmesi ve burada sunduğumuz imkanlar noktasında belediyemizin katkıları var."

"K2: Bizim bir başka kurum ile protokol ve işbirliğimiz olmadı. Şuanda ilçe belediyemizin bünyesinde çalışmalarımız yürüyor."

"K3: Burada dört yerle işbirliğimiz var. Burada bir protokolde var. Dört farklı kurumla işbirliğimiz var."

Belediyelerin STEM merkezlerine önemli bir destek sağladığı görülmektedir (Tablo 8). Belediyelerin maddi ve manevi desteklerine rağmen, üniversiteler bazında desteklerin asgari düzeyde olduğu görülmektedir. Diğer yerel paydaşların ise STEM merkezlerine destekleri yok denecek kadar az seviyede olduğu görülmüştür. Bu durumun, STEM eğitimi farkındalığının toplum nezdinde istenilen düzeylere ulaşmadığından kaynaklandığı söylenilebilir. STEM eğitim yaklaşımı, tüm dünya için bu kadar önem arz ederken yerel paydaşların bu merkezlerle işbirliği içinde olmaması düşünülemez. Bu nedenle işbirliği protokolleri geliştirerek, yerel paydaşlarla STEM merkezleri etkileşim içerisinde olmalıdır. Bu sayede kaynaklar, en verimli şekilde kullanılarak istenilen başarı düzeyi yakalanabilir. STEM merkezlerinin iç ve dış paydaşlarla olan etkileşim sürecine yönelik bilgiler Tablo 9'da verilmiştir.

\section{Tablo 9. STEM Merkezlerinin İç ve Dış Paydaşlarla Olan Etkileşim Süreci}

\begin{tabular}{ll}
\hline \multirow{2}{*}{ 1.Merkez } & $\begin{array}{l}\text { Merkez eğitim verdiği öğretmenlerle öğrencilere yönelik STEM etkinlikleri geliştirme konusunda çalışmalar sürdür- } \\
\text { mektedir. Dış paydaşlardan belediye ile maddi destek anlamında etkileşim süreci sınırlı kalmaktadır. }\end{array}$ \\
\hline 2.Merkez & $\begin{array}{l}\text { Merkez İngiltere UCL (Universty Collage London) ile ortak STEM projesi yürütmektedir. Merkez, ilçede bulunan okul- } \\
\text { larla işbirliği içerisinde kuruma devam edecek öğrencilerin devam ve takiplerini sağlamaktadır. }\end{array}$ \\
\hline 3.Merkez & STEM eğitimi verilen 26 okulla etkileşim süreci devam etmektedir.
\end{tabular}

Tabloda verilen bilgiler katılımcıların aşağıdaki ifadelerini destekler niteliktedir;

“K2: İngiltere UCL (Universty Collage London) görev yapan bir hocamız ile ortak yürüttüğümüz bir projemiz var. Ayrıca ilçeden merkezimize öğrenci gönderen okullarımızla işbirliğimiz var. Öğrencilerin seçimi ve eğitim sürecinde takibi konusunda sürekli iletişimimiz var. Ayrıca paydaşlarımızla işbirliği yaparak merkezde verdiğimiz eğitim kalitesinin artması içinde çalışmalar sürdürüyoruz."

"K3: STEM eğitimimize katılan öğretmenlerimizin bulunduğu 26 okul ile işbirliğimiz devam ediyor. Bu okullarımıza materyal desteği de sağladık."

STEM merkezlerinden beklenilen başarının yakalanabilmesi için iç ve dış paydaşların destekleri önem arz etmektedir. Öğretmen ve öğrencilerin İç ve dış paydaşlarla yapılacak olan bu çalışmaların, STEM yeterliliklerinin arttrılması ve güncel tutulması amacına hizmet edebileceği söylenilebilir.

İ̧̧ ve dış paydaşlarla ortaklaşa yürütülecek STEM projeleri, aralarındaki etkileşimi de olumlu yönde etkileyebilir. STEM merkezlerindeki rehberlik faaliyetlerinin işleyiş sürecine yönelik bilgiler Tablo 10'da verilmiştir. 
Tablo 10. STEM Merkezlerinin Rehberlik Faaliyetlerinin İşleyiş Süreci

\begin{tabular}{ll}
\hline 1.Merkez & $\begin{array}{l}\text { Merkez, STEM eğitimi verdiği öğretmenlere yönelik okullarında STEM'in ders programlarına entegrasyonu konusun- } \\
\text { da rehberlik faaliyetleri sürdürmektedir. Fakat kuruma devam eden öğrencilere yönelik herhangi bir rehberlik faali- } \\
\text { yetleri bulunmamaktadır. }\end{array}$ \\
\hline 2.Merkez & $\begin{array}{l}\text { Öğrencilerin STEM kariyer mesleklerine yönelmelerine yönelik aktif bir rehberlik faaliyeti yürütülmektedir. } \\
\text { 3.Merkez }\end{array}$ \\
$\begin{array}{l}\text { STEM eğitimi verilen öğretmenlere STEM eğitiminde kullanılabilecek malzemelerin tamiri ve desteği konusunda reh- } \\
\text { berlik faaliyetleri devam etmektedir. }\end{array}$
\end{tabular}

Tabloda verilen bilgiler katılımcıların aşağıdaki ifadelerini destekler niteliktedir;

“K1: Merkezimizde öğretmen eğitimlerini sürdürmekteyiz. Burada bizim eğitimlerimize kattlan öğretmen arkadaşlarımıza STEM'in ders planlarına entegrasyonu konusunda rehberlik yapıyoruz. Rehberlik yapabilmek için yüz yüze faaliyetler yürüttüğümüz gibi mail vb. iletişim araçlarını da kullanıyoruz."

STEM merkezleri rehberlik faaliyetleri (Tablo 10) incelendiğinde, STEM merkezlerin öğretmenlere ya da sadece öğrencilere yönelik rehberlik faaliyeti içinde oldukları görülmektedir. STEM eğitim yaklaşımından beklenilen başarının yakalanabilmesi için öğretmenlerin STEM mesleki yeterliliklerinin artırılmasının yanı sıra öğrencilerin de STEM yaşam becerilerinin desteklenmesi ve STEM kariyer meslekleri konusunda bilinçlendirilmeleri gerekmektedir. STEM merkezlerinin etkinlik süreleri hakkındaki bilgiler Tablo 11'de verilmiştir.

\section{Tablo 11. STEM Merkezlerinin Etkinlik Uygulama Zamanları}

1.Merkez Merkezde randevu sistemi ile belirlenen esnek çalışma saatleri içerisinde etkinlikler gerçekleştirilmektedir.

2.Merkez Haftada 6 gün Pazartesi günleri hariç olmak üzere saat 16.30-20.00 arasında hizmet vermektedir.

3.Merkez Öğretmenler hafta içi hizmetiçi eğitim modülüne uygun olarak 17.30-22.00 arasında merkezde eğitimlere gelmektedir.

Tabloda verilen bilgiler katılımcıların aşağıdaki ifadelerini destekler niteliktedir;

“K1: Burası çok büyük bir şehir. Ülkemizin en fazla öğrenci ve öğretmen nüfusuna sahip illerinden biriyiz diyebiliriz. Biz çalışma ve etkinlik saatlerimizi bu noktada esnek belirledik. Öğrencilerimiz internet sitemiz üzerinden randevu alarak değişik zaman periyotlarında katlım sağlıyorlar. Bizde öğrenci ve öğretmen eğitimleri dışında yürüttüğümüz diğer çalışmalarımızda zaman ve mesai gözetmeden çalışmalarımızı sürdürüyoruz."

Tablo 11 incelendiğinde merkezlerin okul saatleri dışında hizmet verdikleri görülmektedir. STEM Merkezleri yedi gün hizmet verebilecek şekilde kurgulanmasının merkezden faydalananlar açısından olumlu olacağı söylenilebilir. Okul öğretmenleri ile STEM merkezi öğretmenleri işbirliği içinde çalışarak öğrenciler okul saatleri içinde de STEM merkezinde etkinlikler yapabilmelidirler. Böylelikle öğrenciler, STEM merkezlerini okuldan kopuk bir yer olarak görmeyeceklerdir. Öğrenciler, okulda edinmiş oldukları bilgileri STEM merkezlerinde uygulamaya çevirme firsatı yakalayacaktır. STEM merkezlerinden yararlanan öğrencilerin sınıf seviyeleri hakkındaki bilgiler Tablo 12'de verilmiştir.

\section{Tablo 12. STEM Merkezlerinden Yararlanan Öğrencilerin Sınıf Seviyeleri}

\begin{tabular}{ll}
\hline 1.Merkez & Merkeze okulöncesinden lise son sınıf seviyesine kadar her sınıf seviyesinden öğrenci gelmektedir. \\
\hline 2.Merkez & Merkeze 3.sınıftan başlayarak 10. Sınıfa kadar öğrencilere eğitim verilmektedir. \\
\hline 3.Merkez & $\begin{array}{l}\text { Merkeze her sınıf düzeyinden öğrenciler gelebilmektedir. Öğrencilerin yanı sıra öğretmen eğitimlerine de merkez- } \\
\text { de ağırlık verilmektedir. }\end{array}$ \\
\hline
\end{tabular}

Tabloda verilen bilgiler katılımcıların aşağıdaki ifadelerini destekler niteliktedir;

“K1: Merkezimiz az önce gözlem ve incelemede gördüğünüz üzere okulöncesinden lise son sınıf seviyesine kadar her eğitim kademesinden her sınıftan öğrencimize destek verebilecek şekilde oluşturulmuştur. Merkezimizde randevu sitemiyle kabul ettiğimiz her sınıf seviyesinden öğrencimiz faydalanmaktadır."

Tablo 12'ye bakıldığında her sınıf seviyesindeki öğrencilerin STEM merkezlerinden yararlanma düzeyinin oldukça sınırlı kaldığı görülmektedir. STEM merkezleri okul öncesinden ortaöğretime hatta yükseköğretim kademesine kadar tüm öğrencileri kapsayacak şekilde kurgulanmalıdır. Böylelikle öğrenciler, küçük yaştan itibaren STEM becerilerini geliştirmeye başlarlar. Elde edilen bu beceriler, ileriki yıllarda onların daha üretken bireyler olmasını sağlayacaktır. Bu nedenle STEM merkezleri her sınıf seviyesindeki öğrencinin yararlanabileceği merkezler olmalıdır. STEM merkezlerinde yapılan sosyal, kültürel, toplumsal ve sportif faaliyetlere yönelik bilgiler Tablo 13'te verilmiştir. 


\section{Tablo 13. STEM Merkezlerindeki Sosyal, Kültürel ve Sportif Faaliyetler}

Merkez sosyal sorumluluk projeleri yürütmektedir. STEM ve Bilim Merkezi'ne başvuran bir çocuğa robot el tasarla-

1.Merkez narak takılmıştır. Bunun yanı sıra kurum uluslarası robot yarışmalarına katılmaktadır. FIRST Global Challenge (FGC) yarışmasında STEM merkezi ülkemizi temsil etme başarısını göstermiştir.

2.Merkez Kurumda akıl oyunları turnuvaları düzenlenmektedir.

3.Merkez Merkezde eğitim alan öğretmenler ile bilişim iftarları ve bilim festivalleri düzenlenmiştir.

“K1: Bizim yakın bir zamanda bir kız çocuğumuza robot el tasarlayıp takma gibi bir sosyal sorumluluk projemiz oldu. Bu yerel medyamızda yer aldı. Tabi bu süreçte gece ve hafta sonları geç saatlere kadar merkezde çalıştık. Bunun dışında FIRST Global Challenge (FGC) yarışmasında STEM merkezi ülkemizi temsil etme başarısını göstermiştir. Bu yarışma ile de medyada yer aldık. Öğrencilerimize çok farklı bir deneyim yaşattik."

STEM merkezlerinin sosyal, kültürel ve sportif faaliyetleri, Tablo 13’te görüldüğü üzere oldukça sınırlı gözükmektedir. Bu durumun merkezlerin yeni kurulması ile açıklanabilir. Süreç içerisinde merkezlerde yapılacak projeler, bu alandaki eksikliklerin giderilmesinde etkili olabilir. STEM eğitim yaklaşımına uygun olarak geliştirilen her projeyle ortaya konan ürünlerin toplum hizmeti kapsamında da değerlendirilebileceğini söylemek yanlış olmayacaktır.

\section{STEM Merkezlerine Yönelik Yapılandırılmış Gözlem Formuyla Elde Edilen Bulgular}

STEM merkezilerinin şehirlerdeki konumları hakkındaki bilgiler Tablo 14'te verilmiştir.

\section{Tablo 14. STEM Merkezlerinin Şehirdeki Konum Bilgileri}

\begin{tabular}{ll}
\hline 1.Merkez & Merkez şehir merkezinde bulunmaktadır. \\
\hline 2.Merkez & $\begin{array}{l}\text { Merkez şehir dışında bir yerleşim bölgesinde bulunmaktadır. Ancak ulaşım sıkıntısı yaşanmamaktadır. Öğrencilerin } \\
\text { merkeze geliş-gidişleri veliler tarafindan sağlanmaktadır. }\end{array}$ \\
\hline 3.Merkez & Merkez ulaşım yönünden merkezi konumda yer almaktadır. \\
\hline
\end{tabular}

Tablo 14 incelendiğinde, STEM merkezlerinin ulaşım yönünden sıkıntılı olmadıkları görülmektedir. Öğrencilerin ve öğretmenlerin STEM merkezlerden yararlandıkları zaman dilimleri (genellikle okul dışı) düşünüldüğünde STEM merkezlerinin, şehir merkezlerinde okul yoğunluğunun yüksek olduğu yerlerde planlanması daha doğru olacaktr. Ayrıca taşradaki öğretmen ve öğrencilerimizin STEM merkezlerinden daha fazla faydalanabilmesi için servis hizmeti de sunulabilmelidir. STEM merkezlerinin fiziki yapıları hakkındaki bilgiler Tablo 15 'te verilmiştir.

\section{Tablo15. STEM Merkezlerinin Fiziki Özellikleri}

Merkez 5 katlı olup 2 konferans salonu, 9 sınıf ve 3 bireysel çalışma tasarım sınıfindan oluşmaktadır. Merkezde anaokulu, ilkokul ver ortaokul STEM sınıflarından meslek liselerine yönelik endüstriyel robot ve kodlama sınıflarına kadar farklı konsepte oluşturulmuş bilim sınıfları bulunmaktadır. Merkezin bahçesi bulunmamaktadır. Merkezin girişinde 1.Merkez 3D proje tasarımları sergilenmektedir. Merkezin her katında malzeme odası bulunmaktadır. Her kat farklı okul seviyesine göre tasarlanmıştır. Her katta bireysel çalışma atölyesi mevcuttur. Atölyeler maksimum 16 kişi eğitim alacak şekilde dörderli grup çalışması için tasarlanmıştır. Merkezde zeka oyunları atölyesi, anasınıf STEM atölyesi, ilkokul STEM atölyesi, ortaokul STEM atölyesi, liseler için STEM atölyesi mevcuttur. Ayrıca kodlama-robot STEM atölyesi de bulunmaktadır. Merkezde bir adet de yemekhane mevcuttur.

Merkezde "Bir Büyüğümüz" köşesi, “ Kelimeler Dünyası", "Bilimsel Sorgulama”, "Matematiksel Modelleme”, "Proje

2.Merkez Tabanlı Öğrenme Atölyesi”, "Akıl Oyunları”, "Kodlama ve Robotik Atölyeleri” bulunmaktadır. Kelimeler Dünyası Atölyesi'nde öğrencilerin kendilerini rahat hissetmeleri için minderler kullanılmaktadır.

3.Merkez Kurum iki katı bir bina içerisinde yer almaktadır. Öğretmen Akademisi olarak kurgulanmıştır. İlk katta; konferans salonu, çalışma atölyesi ve malzeme odası üst katta; iki atölye sınıfi ve iki idare odası mevcuttur.

STEM merkezlerinin fiziki özelikleri incelendiğinde, STEM merkezlerinde isim olarak farklı sınıflar veya atölyeler oluşturulmuş olsa da benzer etkinlikler yapıldığı gözlemlenmiştir. Sadece bir merkez, öğretmen akademisi olarak kurgulandığı için diğer merkezlerden fiziksel farklııklar göstermektedir. STEM merkezlerinde yapılan incelemeler sonucunda STEM merkezleri için en az dört atölyenin (Robotik ve Kodlama Atölyesi, 3D Modelleme Atölyesi, Proje Temelli Öğrenme Atölyesi ve Medeniyet ve Kültür Atölyesi) STEM etkinlikleri için gerekli olduğu görülmüştür. Ayrıca STEM merkezleri için akıl oyunları sınıfinın, öğretmen eğitimleri için bir konferans salonunun ve materyaller için odaların olmasının işlevsel olacağı söylenilebilir. STEM merkezlerinde etkinliklerde kullanılan materyaller ve yazılımlar hakkındaki bilgiler Tablo 16 'da verilmiştir. 
Tablo 16. STEM Merkezlerinde Kullanılan Materyaller ve Yazılımlar

\begin{tabular}{|c|c|c|}
\hline & Kullanılan Materyaller & \\
\hline 1.Merkez & $\begin{array}{l}\text { Merkezde fischer technık yapı setleri, lego ve ardunio robot setle- } \\
\text { ri, fen laboratuvar malzemeleri, üç boyutlu yazıılar ve bilgisayar- } \\
\text { lar kullanılmaktadır. }\end{array}$ & $\begin{array}{l}\text { 3D Modelleme için Tincercat programı kullanıl- } \\
\text { maktadır. }\end{array}$ \\
\hline 2.Merkez & $\begin{array}{l}\text { Merkezde TÜBITAK yayınları ve belediye tarafindan hazırlanan ya- } \\
\text { yınlar kullanılmaktadır. Lego robot setlerinin yanı sıra günlük ya- } \\
\text { şamda kolaylıkla elde edilebilecek materyallerde kullanılmaktadır. }\end{array}$ & \\
\hline 3.Merkez & $\begin{array}{l}\text { Fischer technik yapı setleri, vex robot setleri, ardunio setleri kul- } \\
\text { lanılmaktadır. }\end{array}$ & Fıscher technik yazılımları, vex ve scratch \\
\hline \multicolumn{3}{|c|}{$\begin{array}{l}\text { STEM merkezlerinde kullanılan materyaller incelediğinde, farklı isimlerde materyallerin olduğu görünmektedir. İsim- } \\
\text { r farklı olsa da materyallerin aynı amaç için kullanıldığı söylenebilir. STEM eğitim yaklaşımına özgü ticari amaçlı birçok } \\
\text { lateryal geliştirilmiş olsa da bu materyalleri direkt olarak STEM eğitim materyali olarak değerlendirmek yanlış olacak- } \\
\text { r. STEM eğitim yaklaşımına göre hazırlanan eğitim programının içeriğine göre bu materyallerin STEM eğitim materyal } \\
\text { zelliği kazanacağı unutulmamalıdır. STEM eğitim materyali, bir şişenin kapağı olabileceği gibi bir mikro denetleyic } \\
\text { artta olabilir. Ancak kurulacak STEM merkezlerinde; yapı setlerinin, robotik ve kodlama uygulamaları için bilgisayarla- } \\
\text { n, akıl oyunları setlerinin, grup çalışmaları ve bireysel çalışmalar için hareketli masa ve sandalyelerin, robot malzeme- } \\
\text { rinin, proje sunumları için projeksiyon cihazının, modelleme için 3D yazıcıların olmasının yararlı olacağı söylenilebilir. }\end{array}$} \\
\hline
\end{tabular}

\section{Sonuç ve Öneriler}

Sonuç olarak, STEM eğitim merkezleri idari ve yapısal açıdan farklılık gösterebilmektedir. Araştırmada incelenen üç STEM merkezinin kamu hizmetleri ve öğretim çerçevesinde yapılandırıldıkları görülmektedir. Bu merkezlerin görev, sorumluluk ve idari yapılarını net bir şekilde ortaya koyan mevzuat yoktur. Fakat Karahan (2017), STEM eğitim merkezlerinin içerisinde konumlandırıldığı toplumda STEM eğitiminde olumlu bir değişime yol açabilmesi için öncelikle bu merkezlerin görev, sorumluluk ve yapılarının net bir şekilde ortaya konması gerektiğini ifade etmektedir. Ayrıca, STEM eğitim merkezlerinin çalışma, usul ve esaslarını belirleyen bir çerçeve mevzuat da yoktur. Araştırma sürecinde incelenen STEM eğitim merkezlerinin ortak noktaları da kısıtıdır. Ülkemizde STEM eğitim modelinin yaygınlaştrılması adına bu merkezlerin çalışmaları çok büyük önem arz etmektedir. Ayrıca bu süreçte bu birimlere devlet kaynakları kullanılarak yatırımlar yapılacağı da göz önünde bulundurulduğunda, STEM eğitim merkezlerinin bilimsel ölçüt ve kriterler çerçevesinde kurulması son derece önemlidir.

Kurulacak STEM merkezleri için stratejik plan olmazsa olmazlar arasındadır. 5018 sayılı kanunda stratejik plan; kamu idarelerinin orta ve uzun vadeli amaçlarını, temel ilke ve politikalarını, hedef ve önceliklerini, performans ölçütlerini, bunlara ulaşmak için izlenecek yöntemler ile kaynak dağılımlarını içeren plan olarak tanımlanmıştır (www.mevzuat.gov. tr/MevzuatMetin/1.5.5018.doc). Merkezler, bu plan sayesinde gelecek için yol haritası çizebilecek ve kendilerini güncelleyebileceklerdir. Stratejik planlama, merkezlerin STEM alanındaki gelişmeleri yakından takip etmesi ve bu alandaki güncelliklerini koruyabilmeleri açısından da önem arz etmektedir. Stratejik planın ekip çalışması şeklinde yapılması ve dirik bir süreç olarak görülmesi gerekmektedir. Aksi takdirde stratejik planlamanın başarıya ulaşması neredeyse imkânsızlaşacaktır.

Dünyada STEM eğitim merkezlerinin idari yapıları incelendiğinde; üniversite bünyesinde kurulan merkezler, bağımSIz kişi veya kurumlarca kurulan merkezler ve informel öğrenme ortamları içerisinde yer alan merkezler olmak üzere üç farklı yapılanma görülmektedir. Bu merkezlerden üniversite bünyesinde kurulanlarda ilgili bölümden öğretim üyeleri, bağımsız kişi ve kurumlarca kurulan merkezlerde kurucu kişi ve kişilerle birlikte misyon ve vizyon hedeflerine göre seçtiği kişiler, informal öğrenme ortamları içerisinde yer alan merkezlerde STEM eğitimi alanında lisansüstü eğitim almış araştırmacılar yer almaktadır (Karahan, 2017). İncelenen merkezler, bir ana koordinatör öğretmen ve ona yardımcı diğer koordinatör öğretmenler etrafinda faaliyet göstermektedir. Tüm okul seviyelerinden öğretmenlerin bulunmaması, merkezlerin zayıf yönü olarak değerlendirilebilir. Ülkemizde STEM merkezlerinin kurulabilmesi için yasal bir zeminin oluşmaması, bu merkezde görev yapacak öğretmenlerin görevlendirilmelerinde sıkıntılara neden olmaktadır. Bazı milli eğitim müdürlükleri bu soruna, öğretmenleri AR-GE birimine görevlendirip oradan da STEM merkezi bünyesinde toplayarak çözüm üretmişlerdir. Ancak bu merkezlerde görev yapan öğretmenlerin maddi kayıplarına herhangi bir çözüm bulamamışlardır. Ülkemizde STEM merkezleri kurulması, Bilim ve Sanat Merkezleri gibi yasal bir zemine kavuşturulmaIıdır. Böylelikle bu merkezlerde görev yapacak öğretmenlerin çalışma usul ve esasları netlik kazanabilir. Bu merkezlerin 
organizasyon yapıları bir ana koordinatör ve alt koordinatörlükler (Okul öncesi, Illkokul, Ortaokul ve Lise STEM koordinatörlükleri) şeklinde yapılandııılabilir. Koordinatör öğretmenler, bu merkezlerde tam zamanlı olarak görevlendirilebilir. STEM eğitim yaklaşımına gönül veren öğretmenler de yarı zamanlı olarak görevlendirilerek merkezden faydalanmaları sağlanabilir. Bu sayede her okul seviyesinden öğretmenin STEM merkezlerinde hizmet vermesi sağlanmış olacaktır.

STEM merkezlerinin yasal bir zemine kavuşması gerekliliği burada da karşımıza çıkmaktadır. Bu yasal zeminle birlikte, STEM merkezlerinin hangi sınıf seviyelerine hizmet verecekleri, öğretmen eğitimlerinin STEM merkezlerinde olup olmayacağı gibi karmaşıklıklar giderilmelidir. STEM merkezleri için esnek bir çerçeve bir programı oluşturulmalı ve hedefler belirlenmelidir. Ancak bu hedeflere ulaştıracak stratejiler esnek bırakılmalıdır. Bu programın oluşturulması sürecinde; uzman akademisyenler, il genelinde STEM eğitimine katılan öğretmenler ile öğrenci ve velilerinin katılacağı "STEM Program Geliştirme Çalıştayları" düzenlenebilir. Bu çalıştaylar ile STEM merkezlerinde uygulanacak programların müfredatlarla ilişkili etkinliklere dönüştürülmesi; STEM kariyer meslekleri; ülkemizin geleceği düşünülerek oluşturulan uygulamaların yaygınlaştırılması ve geliştirilmesi; toplumdaki her bir bireye yönelik STEM becerilerinin kazandııılması; kültür ve medeniyetimizdeki değerlerin tanıtımasına yönelik etkinliklerin planlanması amaçlanabilir.

Milli Eğitim Bakanlığı nezdinde STEM hizmet içi eğitim kursları düzenlenmeli ve STEM eğitim yaklaşımı, müfredat programlarıyla ilişkilendirilerek sınıf ortamına taşınmalıdır. Okul seviyelerine göre illerde STEM Eğitim Çalıştayları düzenlenerek, STEM öğretmenleri bir araya getirilmeli, STEM etkinlik örnekleri sergilenmeli, STEM alanında çalışan akademisyenlerle söyleşiler gerçekleştirilmelidir. Böylelikle STEM eğitiminin farkındalık seviyesi ve STEM merkezlerinin etkililiği giderek artacaktır. Ayrıca kurum ve kuruluşların maddi eksikliklerin tamamlanması konusundaki farkındalıklarının artması da bu merkezlere olan destekleri artracakttr.

Inceleme yapılan STEM merkezlerinden elde edilen veriler, STEM Eğitim Modelinin hedefleri ve dünyadaki uygulamaları göz önünde bulundurulduğunda; model olarak kurulacak STEM Merkezinin aşağıdaki nitelikler dâhilinde planlanmasının uygun olacağı düşünülmektedir:

STEM merkezinin misyon, vizyon ve hedeflerinin belirlendiği bir stratejik planı olmalıdır.

STEM merkezinin organizasyon yapısı koordinatörlük ve alt koordinatörlükler şeklinde belirlenmelidir. Bu madde doğrultusunda merkezde görev yapacak öğretmenlerin görev, sorumluluk, çalışma usul ve esasları bir yönerge ile netleştirilmelidir.

STEM merkezinin işleyişi süreç yönetim modelleri ile sürekli olarak gözden geçirilerek, iyileştirilmesi düşünülen yönleri revize edilmelidir. Bu bilgi ışı̆ıında alanında uzman akademisyenler, alan uzmanı öğretmenler ve kurum personeli ile haftalık ve aylık değerlendirme toplantıları planlanmalı ve yapılmalıdır.

STEM merkezinde izlenecek eğitim-öğretim programı oluşturulmalıdır. Bu programın oluşturulması sürecinde; uzman akademisyenler, il genelinde STEM eğitimlerine katılan öğretmenler, öğrenci ve velilerin katııldığ “STEM Program Geliştirme Çalıştayı" düzenlenmelidir. Bu çalıştayda merkezde uygulanacak programın müfredat ile ilişkili etkinliklere dönüştürülmesi, öğrencilerimize STEM kariyer meslekleri ve ülkemizin geleceği için önemini kavratan uygulamaların geliştirilmesi, toplumdaki her bir bireye yönelik STEM becerilerinin kazandırılması, kültür-medeniyetimizdeki değerlerin tanıtılmasına yönelik etkinliklerin planlanması amaçlanmalıdır.

STEM merkezlerinden faydalan öğrenciler, buradaki mezuniyetlerinden sonra da takip edilmelidir. STEM merkezleri, gerekli gördüğü takdirde bu öğrencilerden destek almalıdır.

STEM merkezleri, il genelindeki yerel paydaşlarla işbirliği protokolleri geliştirerek etkileşim içerisinde olmalıdır.

STEM merkezleri, eğitim verdiği öğretmenlere ve öğrencilere STEM yeterliliklerinin arttırılması konusunda sürekli rehberlik etmelidir.

STEM merkezleri, şehir merkezinde ulaşım sıkıntısı olmayan bir konumda olmalıdır. Ayrıca taşradaki öğretmen ve öğrencilerimizin faydalanabilmesi için servis hizmeti de sunulmalıdır.

STEM merkezleri, fiziki yapı olarak en az dört atölye, bir akıl oyunları sınıfi; öğretmen eğitimleri için eğitim salonu, malzeme odaları ve koordinatörlük birimlerinden oluşmalıdır. Kurumda yer alacak atölyeler aşağıdaki gibi belirlenebilir:

- Robotik ve Kodlama Atölyesi.

- 3D Modelleme Atölyesi

- Proje Temelli Öğrenme Atölyesi

- Medeniyet ve Kültür Atölyesi 
Etkinliklerde kullanılacak materyaller için yapı setleri, robotik ve kodlama uygulamaları için bilgisayarlar, akıl oyunları setleri, grup çalışmaları ve bireysel çalışmalar için hareketli masa ve sandalyeler, robot malzemeleri, proje sunumları için projeksiyon cihazı, 3D modelleme için yazıcılar ve süreç içinde gerekli olabilecek materyallerin bulundurulması STEM eğitiminin niteliğini artıracaktır. Bu materyaller olmadan da STEM eğitimi yapılabileceği unutulmamalıdır. STEM eğitiminde süreç, var olan materyallerden maksimum verimlilik alınabilecek şekilde tasarlanmalıdır.

Etkinliklerde kullanılacak yazılımlar, öğretim programlarına göre belirlenmelidir. Öğretmen ve öğrenciler, bu yazılımlara yönelik eğitimlerden geçirilmelidir.

STEM merkezleri, yedi gün hizmet verebilecek şekilde kurgulanmalıdır. Öğretmen ve öğrenci eğitimleri farklı günlerde planlanmalıdır. Ayrıca öğretmen ve öğrencilerin birlikte STEM etkinlikleri yapabileceği saatler de belirlenmelidir.

STEM merkezleri, anasınıfindan 12.sınıfa, hatta yüksek öğretim kademelerine kadar her seviyeden öğrenciye eğitim verebilecek şekilde tasarlanmalıdır.

STEM merkezlerinde sosyal, kültürel ve sportif faaliyetler de göz ardı edilmemelidir. STEM merkezinde bir ana koordinatör ve 3 alt koordinatörlük kurulmalıdır. Her okul seviyesinden öğretmenler bu koordinatörlüklere bağlı olarak verilen görevleri yapmalıdır. Koordinatörlükler, öğretmen ile öğrenci eğitim süreçlerini planlamalı ve uygulama süreçlerini takip etmelidir.

STEM merkezleri müze gibi sadece ziyaret edilen bir yer değil, sürekli uygulama merkezi olmalıdır. Kazanımları yaşantiya dönüştüren bir kimlik kazanmalıdır. Sadece öğrenci veya öğretmen eğitimi üzerine değil; öğrenci merkezli öğretmen akademisi şeklinde kurgulanması daha doğru bir yaklaşım olacaktır.

\section{Kaynakça}

Akgündüz, D., \& Ertepınar, H. (Eds.). (2015). STEM eğitimi Türkiye raporu “Günün modası mı yoksa gereksinim mi?”. İstanbul Aydın Üniversitesi STEM Merkezi ve Eğitim Fakültesi

Corlu, M. S., Capraro, R. M., and Capraro, M. M. (2014). Introducing STEM education: Implications for educating our teachers in the age of innovation. Education and Science, 39(171), 74-85.

Kamu Malî Yönetimi ve Kontrol Kanunu. Erişim Tarihi: 25.12.2017, http://www.mevzuat.gov.tr/MevzuatMetin/1.5.5018.pdf.

Karahan, E. (2017). STEM Eğitim Merkezleri. S. Çepni (Ed.), Kuramdan Uygulamaya Stem+A+E Eğitimi (ss. 93-113). Ankara: Pegem Akademi

Karasar, N. (2008). Bilimsel araştırma yöntemi (18. Baskı). Ankara: Nobel Yayın Dağıı̆ım.

MEB (2016). STEM Eğitimi Raporu. Erişim Tarihi: 12.11.2017, http://yegitek.meb.gov.tr/STEM_Egitimi_Raporu.pdf.

Thomas, T. A. (2014). Elementary teachers' receptivity to Integrated science, technology, engineering, and mathematics (STEM) education in the elementary grades. (Doctoral dissertation). Retrieved from Proquest. (3625770).

Yıldırım, A. ve Şimşek, H. (2000). Sosyal bilimlerde nitel araştırma yöntemleri (2.baskı). Ankara: Seçkin Yayıncılık.

Yılmaz, H., Koyunkaya, M. Y., Güler, F., ve Güzey, S. (2017). Fen, teknoloji, mühendislik, matematik (STEM) eğitimi tutum ölçeğinin Türkçe'ye uyarlanması. Kastamonu Eğitim Dergisi, 25(5), 1787-1800. 